\title{
Distribution of Dietary Risk Factors in Iran: National and Sub-National Burden of Disease
}

\author{
Negar Zamaninour, PhD'; Moein Yoosefi, MSc ${ }^{2,3}$; Mojdeh Soleimanzadehkhayat, MSc, ${ }^{4,2}$; Forough Pazhuheian, MSc²; Sahar Saeedi \\ Moghaddam, MSc²; Shirin Djalalinia, PhD ${ }^{5,2}$; Nazila Shahbal, BSc ${ }^{2}$; Rosa Haghshenas, BSc ${ }^{2,6}$; Mona Marzban, PhD ${ }^{7,2}$; Arezou Dilmaghani- \\ Marand, MSc'; Ameneh Kazemi, MSc ${ }^{6,2}$; Nasim Hadian, MSc ${ }^{2}$; Hossein Zokaei, MSc ${ }^{2}$; Abbas Pariani, MSc ${ }^{8}$; Mohammad Javad Hajipour, \\ PhD $^{9,2}$; Shirin Hasani-Ranjbar, MD ${ }^{10}$; Farshad Farzadfar, MD, MPH, DSC ${ }^{2,6^{*}}$

\begin{abstract}
'Minimally Invasive Surgery Research Center, Iran University of Medical Sciences, Tehran, Iran
${ }^{2}$ Non-Communicable Diseases Research Center, Endocrinology and Metabolism Population Sciences Institute, Tehran University of Medical Sciences, Tehran, Iran

${ }^{3}$ Department of Biostatistics, Faculty of Paramedical Sciences, Shahid Beheshti University of Medical Sciences, Tehran, Iran

${ }^{4}$ School of Nutritional Sciences and Dietetics, Tehran University of Medical Sciences, Tehran, Iran

${ }^{5}$ Deputy of Research and Technology, Ministry of Health and Medical Education, Tehran, Iran

${ }^{6}$ Endocrinology and Metabolism Research Center, Endocrinology and Metabolism Clinical Sciences Institute, Tehran University of Medical Sciences, Tehran, Iran

${ }^{7}$ Department of Virology, School of Public Health, Tehran University of Medical Sciences, Tehran, Iran

${ }^{8}$ Deputy of Health, Ministry of Health and Medical Education, Tehran, Iran

${ }^{9}$ Persian Gulf Marine Biotechnology Research Center, The Persian Gulf Biomedical Sciences Research Institute, Bushehr University of Medical Sciences, Bushehr, Iran

${ }^{10}$ Obesity and Eating Habits Research Center, Endocrinology and Metabolism Clinical Sciences Institute, Tehran University of Medical Sciences, Tehran, Iran
\end{abstract}

\begin{abstract}
Background: Non-communicable diseases (NCDs) are one of the greatest threats to public health, and have been related to poor quality dietary patterns. This study was conducted to determine the distribution of dietary risk factors in Iran.

Methods: Cross-sectional data was gathered between April and November 2016 from 30,541 eligible adults (out of 31050 individuals who were selected through systematic proportional to size cluster random sampling) living in urban and rural areas, using the WHO-based STEPs risk factor questionnaire. Low intakes of fruits, vegetables, dairy products, and fish, and high intakes of salty processed food (SPF), as well as daily intake of hydrogenated fat (HF) were considered as nutritional risk factors.

Results: At the national level, $82.8 \%(95 \%$ Cl: 82.4-83.2), 57.8\% (95\% Cl: $57.2-58.4), 80.6 \%(95 \% \mathrm{Cl}: 80.1-81)$ and $90.3 \%(95 \%$ Cl: 90-90.6) of participants of all age groups had sub-optimal intakes of fruits, vegetables, dairy products and fish, respectively. Furthermore, $12.8 \%$ (95\% Cl: 12.4-13.1), and 29.4\% (95\% Cl: 28.9-29.9) of respondents had high SPF intakes and HF use, respectively. At the sub-national level, the highest distribution of suboptimal intake of fruits $(97.2 \%$; $95 \% \mathrm{Cl}: 96-98.3)$, vegetables (79.2\%; 95\% Cl: 76.3-82.1) and dairy products (92.9\%; 95\% Cl: 91-94.7) was observed in Sistan and Baluchistan. Except for Boushehr and Hormozgan, the majority of the population of other provinces consumed fish less than twice a week. Similarly, the high intake of SPF was found mostly in the population of Yazd (23.7; 95\% Cl: 20.2-27.2). HF consumption was the highest in North Khorasan (64.2\%; 95\% Cl: 60.3-68.1).

Conclusion: These findings highlight the widespread distribution of dietary risk factors in Iran, which should be a priority for the people and the politicians in order to prevent NCDs.

Keywords: Chronic disease, Non-communicable disease, Nutritional status

Cite this article as: Zamaninour N, Yoosefi M, Soleimanzadehkhayat M, Pazhuheian F, Saeedi Moghaddam S, Djalalinia S, et al. Distribution of dietary risk factors in Iran: national and sub-national burden of disease. Arch Iran Med. 2021;24(1):48-57. doi: 10.34172/aim.2021.08.
\end{abstract}

Received: April 6, 2020, Accepted: October 4, 2020, ePublished: January 1, 2021

\section{Introduction}

Following an appropriate dietary pattern offers an effective way to reduce the burden of chronic ailments. ${ }^{1,2}$ However, people globally have become adapted to food consumption systems which have harmful effects on their health. ${ }^{3}$ There is strong evidence that poor diet quality (sub-optimal daily intake of fruits, vegetables, low-fat milk or dairy, and high intake of hydrogenated fat (HF) and salt, as well as low- frequency consumption of certain foods such as fish) is associated with non-communicable diseases (NCDs), namely type 2 diabetes and cardiovascular disease. ${ }^{4-9}$ Antioxidant compounds, vitamins, minerals and fiber in fruits and vegetables, ${ }^{10}$ in addition to calcium, vitamin $\mathrm{D}$ and leucine derived from dairy products ${ }^{11}$ could explain the related beneficial relationship observed between the intake of such food items and lower risk of several 
disorders. Additionally, protein, omega 3 fatty acids, vitamin $\mathrm{D}$, iodine and selenium in fish all have protective effects on metabolic profiles. ${ }^{12}$ On the other hand, it has been well established that trans fatty acids consumed from hydrogenated oil, as well as high salt intake, are associated with cardiovascular diseases. ${ }^{13,14}$ Interestingly, previous studies have published reports regarding the sub-optimal dietary intake figures in Iranian adults, ${ }^{6}$ although no subnational level data are available. Iran is also facing relatively high rates of diabetes and cardiovascular diseases, ${ }^{15-18}$ which impose direct and indirect health costs on the society. ${ }^{19,20}$ Considering SDGs 3.4 (Sustainable Development Goals) "to reduce the unconditional NCDs probability of death by $30 \%$ by $2030 ",{ }^{21}$ scientists, policymakers and managers at national and sub-national levels need data on risk factor distribution. Identifying various food consumption patterns as modifiable risk factors may be imperative in reducing the risk of multiple chronic illnesses and their future costs. For this reason, in the present study, the aim was to investigate the national and sub-national distribution of certain dietary risk factors by age, sex, socio-demographic, socio-economic variables and medical risk factors in Iran.

\section{Materials and Methods}

This study was a community population-based, crosssectional survey, and was conducted by the NonCommunicable Diseases Research Center group between April and November 2016, using the modified version of WHO-based STEPS (STEPwise approach to Surveillance) risk factor questionnaire. ${ }^{22}$ The target population included adults (male and female) aged 18 and above who lived in urban and rural areas of Iran. It was designed to collect data on 31050 individuals who were selected through systematic proportional to size cluster random sampling; however, a final total of 30541 eligible adults were selected to participate in the study (Figure 1). A signed informed consent form was obtained prior to initiation of the study. The study protocol has been previously published ${ }^{22}$ and included detailed information on setting, data collection, sampling protocol, and the precise controls used for possible errors such as questioner error, non-response

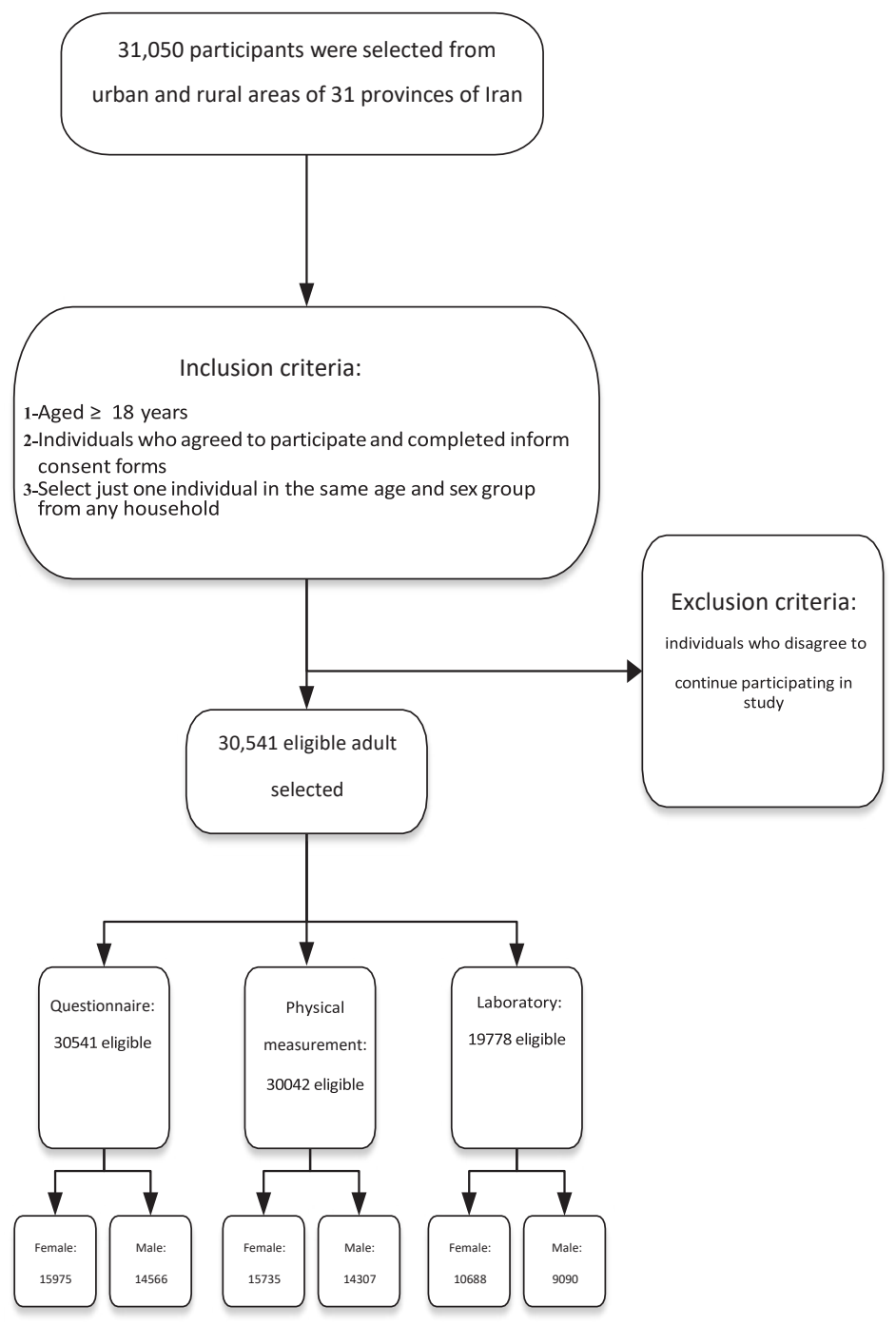

Figure 1. Study Protocol Diagram of Data Collection Process. 
error and error in data entry. ${ }^{22}$ The above-mentioned questionnaire measured the daily consumption of fruits, vegetables, milk or dairy products, type of cooking oil, and the frequency of fish and salty processed foods (SPFs) consumed per week. Current tobacco smoking status, household information, and anthropometric and biological measurements were also recorded. The validity and reliability of the questionnaire have been previously evaluated. ${ }^{22}$

\section{Selection of Dietary Risk Factors}

Six dietary risk factors were selected, all of which have demonstrated associations with chronic diseases. Low intake of fruits ( $<2$ servings/day), low intake of vegetables ( $<3$ servings/day), ${ }^{23,24}$ low intake of dairy products $(<2$ servings/day), ${ }^{25}$ low intake of fish (<twice/week), ${ }^{26}$ high intake of SPF ( $>0$ time/week), ${ }^{27}$ and daily intake of $\mathrm{HF}^{28}$ were considered as nutritional risk factors.

\section{Physical Activity Assessment}

The Global Physical Activity Questionnaire (GPAQ) was used to assess physical activity levels. ${ }^{29}$ The intensity of physical activity was expressed using metabolic equivalents (METs)-minutes per week.

\section{Data Analysis}

The distribution of nutritional risk factors in Iran was examined generally by province, sex, age, education level, marital status, wealth index, lipid profiles, and specific NCDs such as diabetes, cardiovascular disease, and hypertension, and was reported as percentage and frequency. Additionally, missing data was controlled for by applying weightings to participants in the responding sample. Data were analyzed using the STATA statistical software version 14.0 (StataCorp. 2015. STATA Statistical Software: Release 14. College Station, TX: StataCorp LP). Survey data analysis was used to analyze the data.

\section{Results}

Distribution of Dietary Risk Factors at National Level Of those surveyed, 15975 participants (52.3\%) were women and 14566 (47.7\%) were men, of whom 21,493 (70.37\%) lived in urban and 9048 (29.63\%) lived in rural areas. The distribution of dietary risk factors was stratified into socio-demographic characteristics, physical activity and body mass index lipid profiles, and NCDs at the national level (provided in Table 1 and Table 2).

At the national level, 82.8\% (95\% CI: 82.4-83.2), 57.8 \% (95\% CI: 57.2-58.4), 80.6\% (95\% CI: 80.1-81), and $90.3 \%$ (95\% CI: 90-90.6) of the participants of all age groups had sub-optimal intake of fruits, vegetables, dairy products, and fish, respectively. Furthermore, 12.8\% (95\% CI: 12.4-13.1), and 29.4\% (95\% CI: 28.9-29.9) of respondents ate SPFs during the week and used hydrogenated vegetable oil and margarine to cook daily, respectively. Additionally, 83.9\% (95\% CI: 83.3-84.5), 57.1\% (95\% CI: 56.3-57.9), 82.4\% (95\% CI: $81.8-83)$ and $90.3 \%(95 \%$ CI:89.9-90.8) of all female and $81.6 \%$ (95\% CI: 80.9-82.2), 58.7\% (95\% CI: 57.9-59.5), 78.7\% (95\% CI:78.0-79.4) and 90.2 (95\% CI: 89.7-90.7) of all male participants ate less than the recommended portions of fruit, vegetables, dairy products and fish. Likewise, 11.1\% (95\% CI: 10.5-11.6) and 30\% (95\% CI: $29.3-30.7)$ of all females and $14.6 \%$ (95\% CI: 14-15.2) and 28.7\% (95\% CI: 27.9-29.4) of all males consumed SPFs during the week and used hydrogenated vegetable oil and margarine to cook daily.

Furthermore, the consumption of hydrogenated vegetable oil and margarine was higher in rural populations and among people with lower education levels, lower wealth indices, as well as lower body mass index $(\mathrm{BMI}<18.5 \mathrm{~kg} /$ $\mathrm{m}^{2}$ versus $\geq 25 \mathrm{~kg} / \mathrm{m}^{2}$ ). Sub-optimal intake of vegetables ( $<3$ servings/day) was seen in two out of three underweight people. Furthermore, the similarities in the distribution of most of the nutritional risk factors were found in the patient (having diabetes and/or cardiovascular disease and/ or hypertension and/or lipid disorders) and non-patient subgroups. However, the consumption of SPFs was lower in people with cardiovascular diseases and hypertension than in non-patient subgroups.

It is also worth noting that the frequency and percentage of the missing values of each nutritional risk factor was as follows: 602 (1.97) for fruits, 548 (1.79) for vegetables, 663 (2.17) for dairy products, 549 (1.80) for fish, 551 (1.81) for SPFs and 589 (1.93) for oil and fat.

Distribution of Dietary Risk Factors at Sub-National Levels

The highest distribution of dietary risk factors was observed in provinces representing 97.2\% (95\% CI: 96-98.3) of the population for the sub-optimal intake of fruits, $79.2 \%$ (95\% CI: 76.3-82.1) for vegetables, 92.9\% (95\% CI: 91-94.7) for dairy products, $98.3 \%$ (95\% CI: 97.3-99.3) for fish, 23.7\% (95\% CI: 20.2-27.2) for excess SPFs and 64.2\% (95\% CI: 60.3-68.1) for hydrogenated vegetable oil and margarine. While the lowest distribution of dietary risk factors was in the provinces representing 54.1\% (95\% CI: 49.4-58.7) of the population for sub-optimal intake of fruits, 39.3\% (95\% CI: 35-43.7) for vegetables, 59.8\% (95\% CI: 55.9-63.7) for dairy products, $43.4 \%$ (95\% CI: 38.3-48.4) for fish, 5.3\% (95\% CI: 3.8-6.9) for excess SPFs and $9.4 \%$ (95\% CI: 7.3-11.4) for hydrogenated vegetable oil and margarine (Table 3, Figures 2A-E, Figure 3).

\section{Discussion}

The distribution of six dietary risk factors was investigated at the national and sub-national level in Iran. The results at the national level demonstrated that the majority of people in age, sex and BMI specific subgroups had sub- 
号

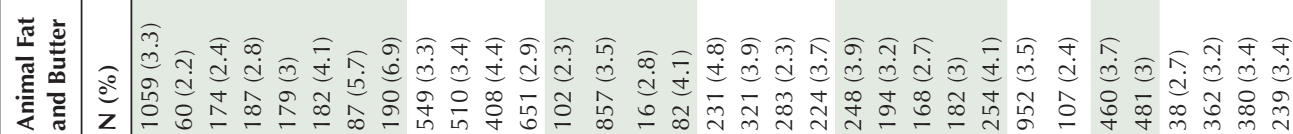

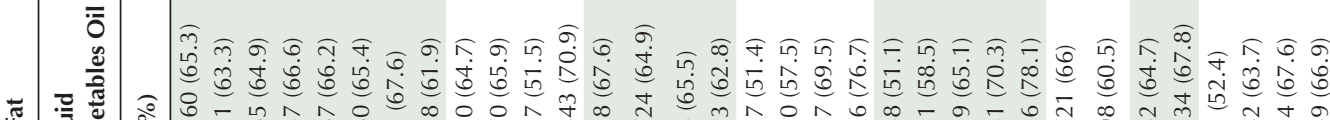

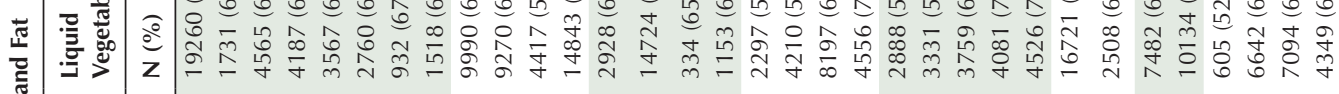

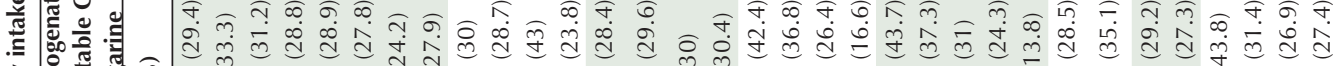

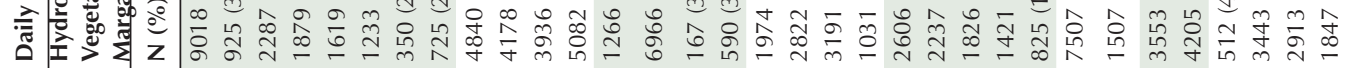

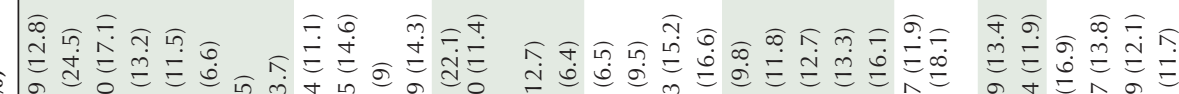

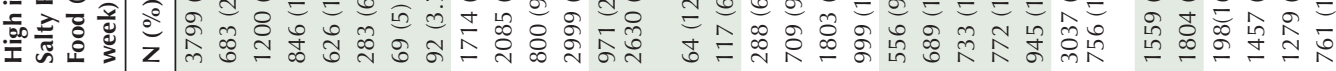

$\frac{\sqrt{5}}{\frac{5}{2}}$

लิต

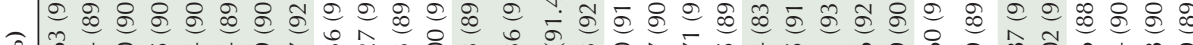

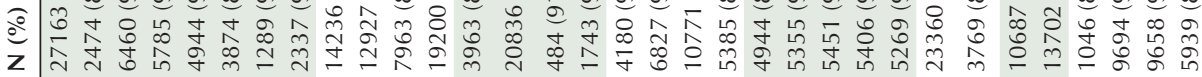
s.

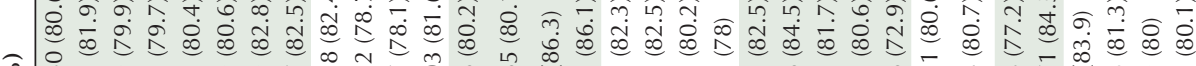
Z

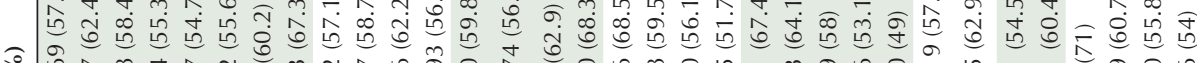
z

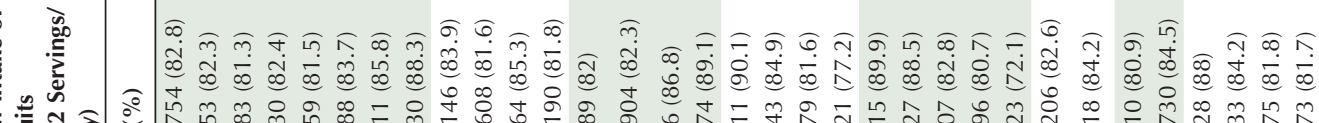

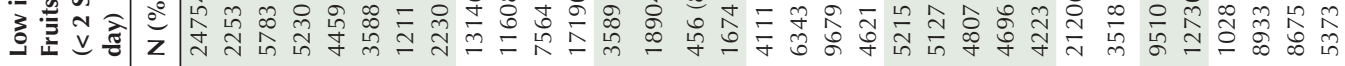

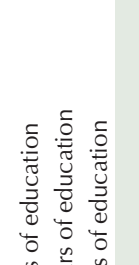

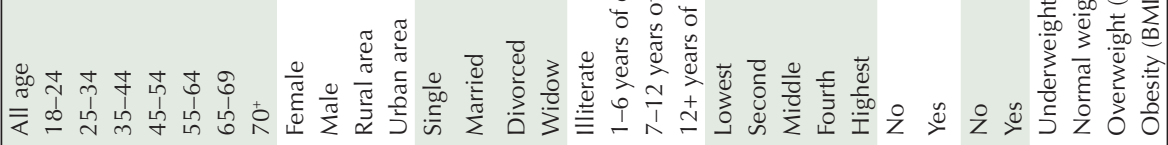

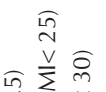

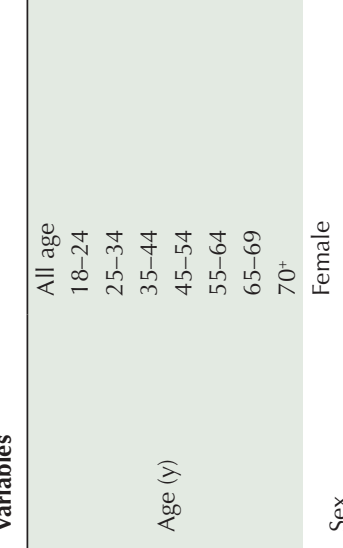

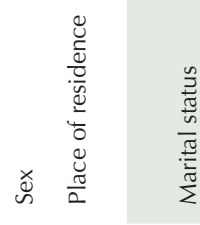
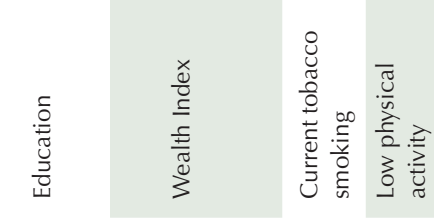

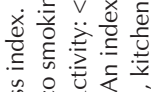




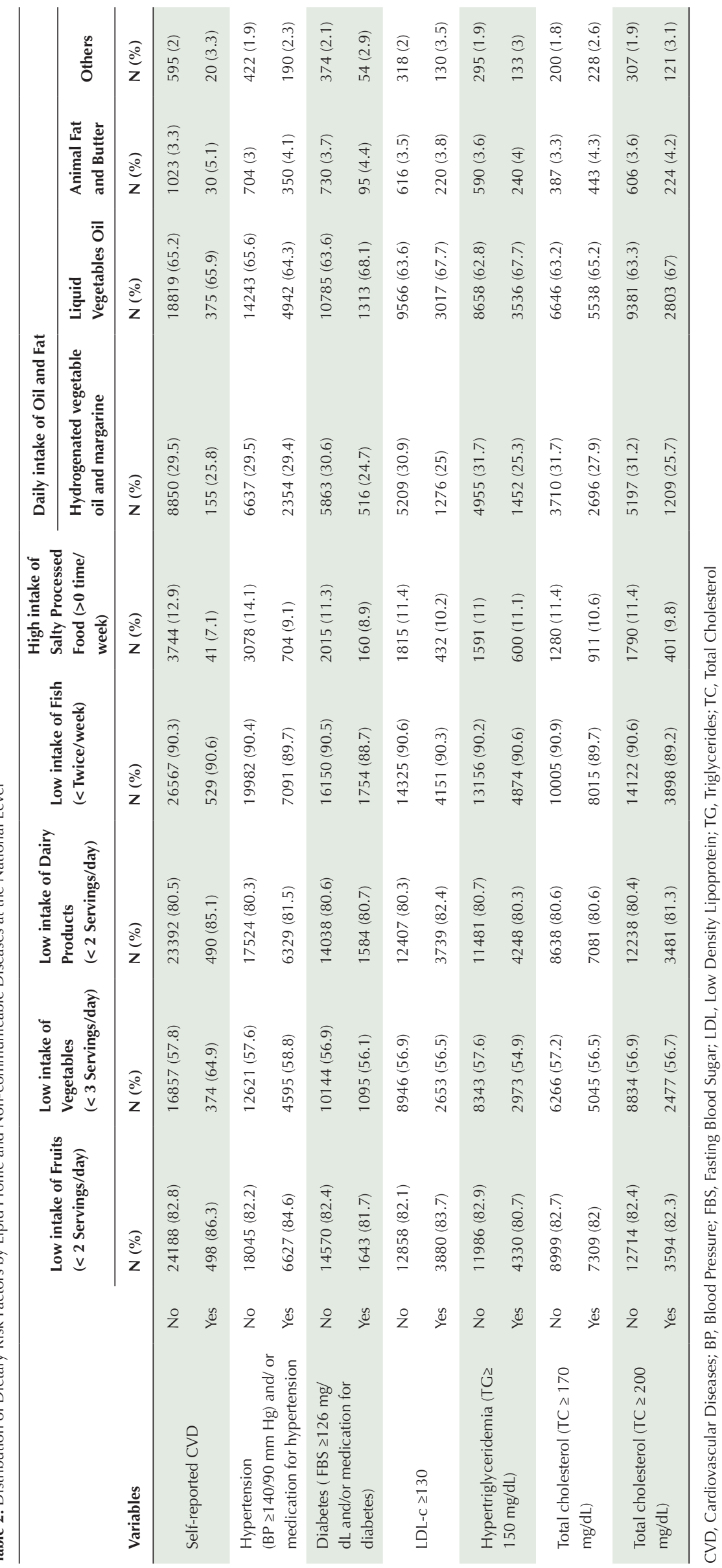




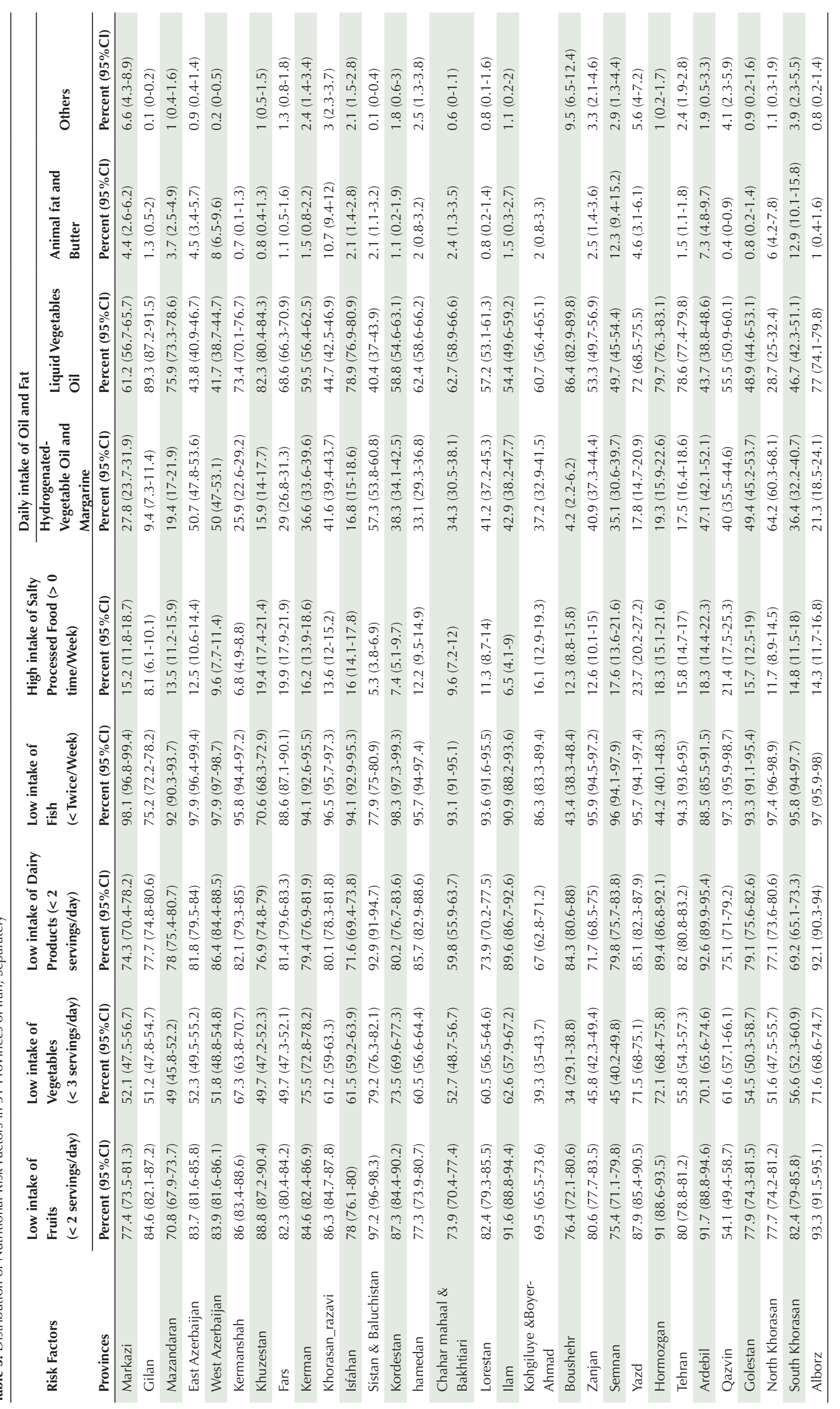


(A)

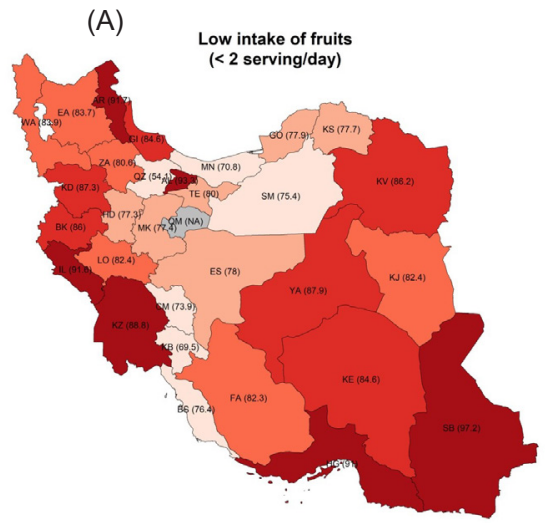

(C)

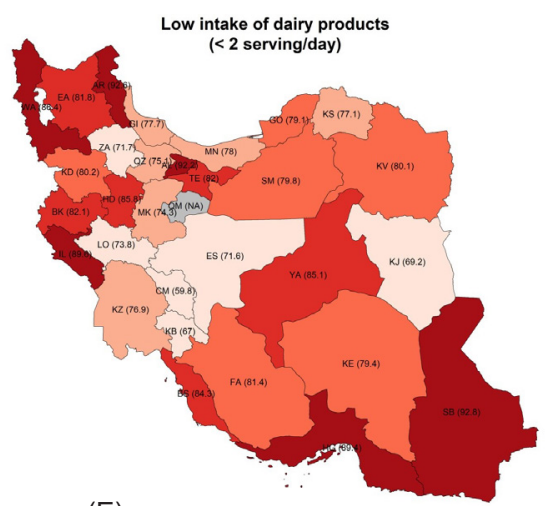

$(\mathrm{E})$

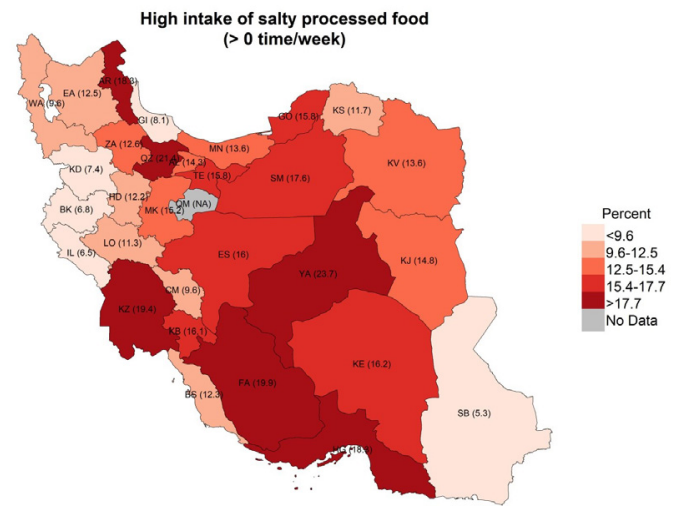

(B)

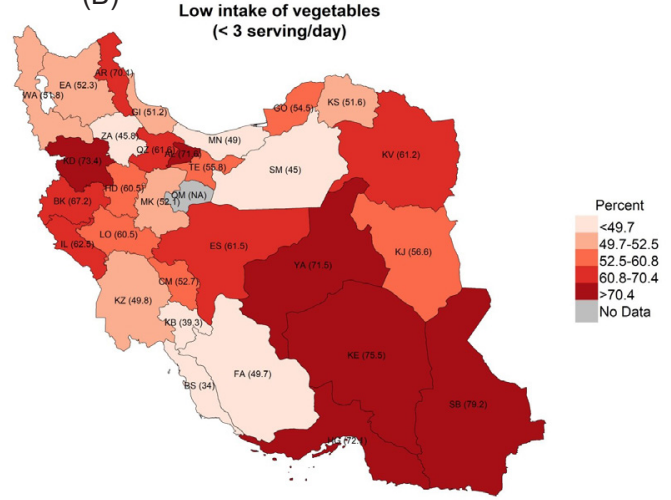

(D)

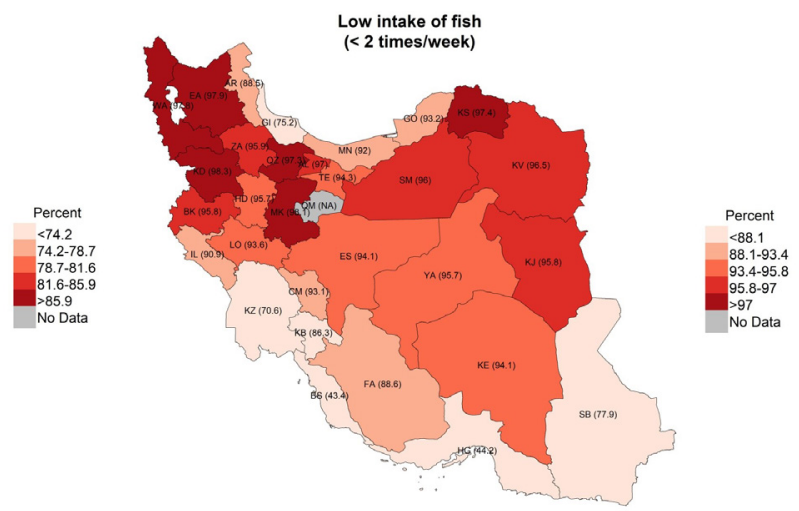

Figure 2. (A) Distribution of low fruit consumption by province, Iran. (B) Distribution of low vegetable consumption by province, Iran. (C) Distribution of low dairy product consumption by province, Iran. (D) Distribution of low fish consumption by province, Iran. (E) Distribution of high salty processed food consumption by province, Iran.

optimal intakes of fruits, vegetables, dairy products, and fish. Overall, $12.8 \%$ of all age groups ate SPFs during the week. Additionally, about one in three respondents in the age and sex subgroups used hydrogenated vegetable oil and margarine to cook. Furthermore, in the BMI subgroups, a higher percentage of underweight people (BMI $<18.5$ $\mathrm{kg} / \mathrm{m}^{2}$ ) had sub-optimal consumption of fruits, vegetables, and dairy products and also used SPFs and HF compared to other BMI subgroups. This may be a reflection of malnutrition in this group of people. Sub-optimal dietary intakes in Iranian adults has been previously reported in recent years. ${ }^{6,30}$ Poor dietary quality is driven by a number of factors affecting inadequate food supply (e.g. food and agricultural policies, food marketing), as well as inadequate food utilization (e.g. education, income, nutritional knowledge, access to the supermarket, and food availability in local stores). ${ }^{31}$ Previous studies in Iran have highlighted the impact of these factors on inappropriate food intakes. ${ }^{32,33}$ As an example, one qualitative study conducted on Iranian men showed that lack of nutritional knowledge, taste preferences for fatty foods and fast food, the influence of friends and peers on youth eating, media advertisements, nutritional transition, women's societal roles, and lack of access to healthy food due to high prices, time limitation, lack of confidence to select healthy foods, and easy access to unhealthy foods were the main obstacles to healthy eating. ${ }^{32}$ In turn, factors such as lack of access to healthy food (due to inadequate knowledge, the high cost 


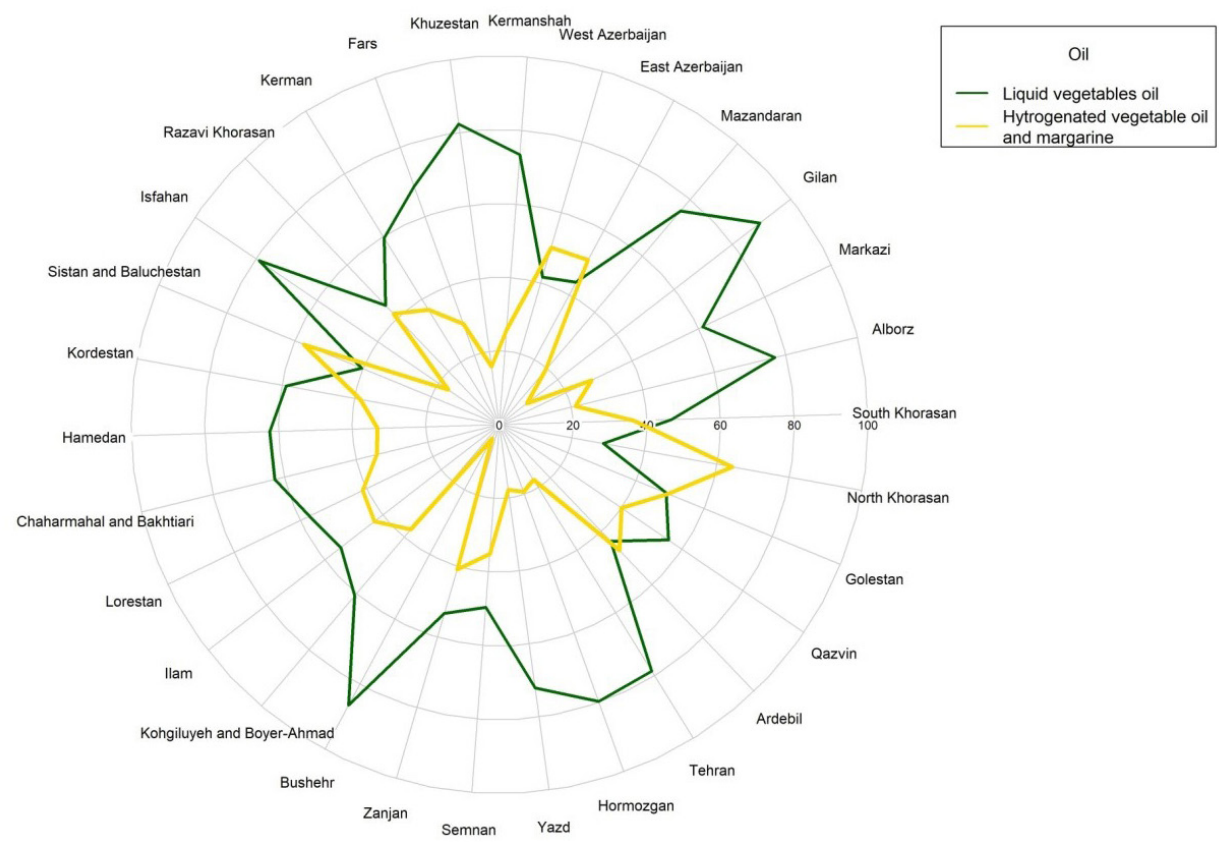

Figure 3. Distribution of oil (Liquid and Hydrogenated) and Margarine Consumption by Province, Iran.

of healthy foods, time limits for preparing healthy foods, poor restaurant hygiene, and the limited variety of healthy foods), interpersonal and cultural effects (e.g. unhealthy behavioral modeling and inappropriate prioritization), and food preferences (personal taste and the limited variety of healthy foods) have been suggested as the major barriers to healthy nutrition among Iranian females. ${ }^{33}$

In spite of the nutritional obstacles mentioned in Iran, there is growing policy attention on increasing fruit and vegetable consumption, limiting salt intake (through mass media education, salt reduction in food industries and restaurants), and reducing fat intake (through public education with an emphasis on reducing fat and oil consumption, as well as encouraging people to use liquid oils in cooking and governmental educational provision about the harmfulness of saturated and trans fatty acids on human health). ${ }^{34}$ Despite these efforts, an alarming distribution of nutritional risk factors for NCDs was also shown across the provinces of Iran (based on Table 3). It seems that inequalities arising from the social, political, cultural, economic and geographical conditions in Iran ${ }^{35,36}$ could be the main cause of the widespread distribution of nutritional risk factors in certain provinces. Multiple lines of evidence converge to support the potential role of socioeconomic status (SES) in making appropriate food choices. $^{37,38}$ Sub-optimal intakes of fruits, vegetables and fish and also consumption of unhealthy fat have been reported among Iranian Kurdish groups with low SES. ${ }^{39}$ Similarly, in a study conducted on Kurdish and Azeri ethnic groups in Urmia, Rezazadeh et al showed that household SES was associated with dietary patterns. ${ }^{40}$ In addition to SES, belonging to racial and ethnic minority groups has also been considered as a factor affecting diet- related inequalities. ${ }^{41}$ As an example, Mexican-American men living in Texas consumed poorer diets (less fruits and vegetables) compared to Latino men in California. ${ }^{42}$ Additionally, food insecurity has been reported to be more prevalent in the Iranian Baluch population compared to Fars ethnic households. ${ }^{43}$ It is worth noting that food insecurity also affects dietary choices. ${ }^{44-46}$ Based on a metaanalysis conducted on the prevalence of food insecurity in Iran, $49 \%$ of households suffer from food insecurity. ${ }^{47}$ Besides these factors, inadequate geographical access to healthy foods is another challenging issue that has been mentioned in previous studies. ${ }^{48,49}$ Greater distances to higher quality food stores are also a major obstacle to accessing healthy foods, especially in low-income areas..$^{50,51}$ On the whole, the current study was a step toward understanding the distribution of some dietary risk factors in order to provide a basis for future studies into the deeper causes of these distributions.

The strength of this study was that the distribution of major nutritional risk factors was investigated at both national and sub-national levels. However, the current study had some limitations, as follows. Firstly, the study was designed to provide general information about nutritional risk factors at national and sub-national levels in Iran, without measuring total energy or fat intake. Secondly, the contribution of nutritional risk factors to the national burden of disease has not been investigated. Thirdly, some important dietary risk factors, such as low intake of whole grains, seafood omega-3 fatty acids, nuts, and seeds, and high intake of processed meat and sugarsweetened beverages, were not included in this study.

In conclusion, there is a large gap between the recommendation and consumption of fruits, vegetables, 
dairy products, fish, SPFs, and sources rich in transfatty acids (hydrogenated vegetable oil and margarine) among the adult population of Iran. Several individual-, community- and national-level factors can explain this gap, which should be considered as a priority for politicians to prevent NCDs.

\section{Authors' Contribution}

General designing of the paper: FF, NZ; Designing methods: FF, NZ, MY, FP, SSM; Analysis: MY, SSM, SHD; Writing primary draft: $\mathrm{NZ}, \mathrm{MS}, \mathrm{NSH}, \mathrm{FP}$; Manuscript revision: FF, RH, MM, HZ, MJH; Administrative process: ADM, AK, NH, AP. All authors are in agreement with the manuscript and declare that the content has not been published elsewhere.

\section{Conflict of Interest Disclosures}

The authors declare that they have no conflict of interest.

\section{Ethical Statement}

This study was conducted according to the guidelines laid down in the Declaration of Helsinki and all procedures were approved by the Ethical Committee of National Institute for Medical Research Development (NIMAD) (ID:IR.NIMAD.REC.1394.032). Additionally, ethical issues including plagiarism, authorship, privacy, conflicts of interest, informed consent, data fabrication, double submission etc have been completely observed by the researchers and authors.

\section{Funding}

The grant of the study comes from the Ministry of Health and Medical Education of Islamic Republic of Iran and National Institute for Health Research. In addition, they had no role in the design, analysis or writing of this article.

\section{Acknowledgements}

The authors would like to express their appreciation for the collaboration of the Deputy for Public Health and Deputy for Research and Technology at the Ministry of Health and Medical Education, the Islamic Republic of Iran's National Institute for Health Research, and many scholars and experts in related fields. They would also like to express their thanks to all of the participants and scientific and executive partners of medical science universities who made this study possible.

\section{References}

1. Aljefree N, Ahmed F. Association between dietary pattern and risk of cardiovascular disease among adults in the Middle East and North Africa region: a systematic review. Food Nutr Res. 2015;59:27486. doi: 10.3402/fnr.v59.27486.

2. Wang H, Deng F, Qu M, Yang P, Yang B. Association between Dietary Patterns and Chronic Diseases among Chinese Adults in Baoji. Int J Chronic Dis. 2014;2014:548269. doi: 10.1155/2014/548269.

3. Forouzanfar $\mathrm{MH}$, Alexander $\mathrm{L}$, Anderson HR, Bachman VF, Biryukov S, Brauer $\mathrm{M}$, et al. Global, regional, and national comparative risk assessment of 79 behavioural, environmental and occupational, and metabolic risks or clusters of risks in 188 countries, 1990-2013: a systematic analysis for the Global Burden of Disease Study 2013. Lancet. 2015;386(10010):2287323. doi: 10.1016/S0140-6736(15)00128-2.

4. de Souza RJ, Mente A, Maroleanu A, Cozma Al, Ha V, Kishibe $\mathrm{T}$, et al. Intake of saturated and trans unsaturated fatty acids and risk of all cause mortality, cardiovascular disease, and type 2 diabetes: systematic review and meta-analysis of observational studies. BMJ. 2015;351:h3978. doi: 10.1136/ bmj.h3978.

5. Tong X, Dong JY, Wu ZW, Li W, Qin LQ. Dairy consumption and risk of type 2 diabetes mellitus: a meta-analysis of cohort studies. Nutrients. 2017;9(9):982. doi: 10.3390/nu9090982.
6. Afshin A, Micha R, Khatibzadeh S, Fahimi S, Shi P, Powles J, et al. The impact of dietary habits and metabolic risk factors on cardiovascular and diabetes mortality in countries of the Middle East and North Africa in 2010: a comparative risk assessment analysis. BMJ Open. 2015;5(5):e006385. doi: 10.1136/bmjopen-2014-006385. Erratum in: BMJ Open. 2019 May 1;9(4):e006385corr1.

7. Qin LQ, Xu JY, Han SF, Zhang ZL, Zhao YY, Szeto IM. Dairy consumption and risk of cardiovascular disease: an updated meta-analysis of prospective cohort studies. Asia Pac J Clin Nutr. 2015;24(1):90-100. doi: 10.6133/apjcn.2015.24.1.09.

8. Powles J, Fahimi S, Micha R, Khatibzadeh S, Shi P, Ezzati $\mathrm{M}$, et al. Global, regional and national sodium intakes in 1990 and 2010: a systematic analysis of $24 \mathrm{~h}$ urinary sodium excretion and dietary surveys worldwide. BMJ Open. 2013;3(12):e003733. doi: 10.1136/bmjopen-2013-003733.

9. Villegas R, Xiang YB, Elasy T, Li HL, Yang G, Cai H, et al. Fish, shellfish, and long-chain n-3 fatty acid consumption and risk of incident type 2 diabetes in middle-aged Chinese men and women. Am J Clin Nutr. 2011;94(2):543-51. doi: 10.3945/ ajcn.111.013193.

10. Liu RH. Health-promoting components of fruits and vegetables in the diet. Adv Nutr. 2013;4(3):384S-92S. doi: 10.3945/ an.112.003517.

11. Hirahatake KM, Slavin JL, Maki KC, Adams SH. Associations between dairy foods, diabetes, and metabolic health: potential mechanisms and future directions. Metabolism. 2014;63(5):618-27. doi: 10.1016/j.metabol.2014.02.009.

12. Tørris C, Småstuen MC, Molin M. Nutrients in fish and possible associations with cardiovascular disease risk factors in metabolic syndrome. Nutrients. 2018;10(7):952. doi: 10.3390/nu10070952.

13. Mozaffarian D, Katan MB, Ascherio A, Stampfer MJ, Willett WC. Trans fatty acids and cardiovascular disease. N Engl J Med. 2006;354(15):1601-13. doi: 10.1056/NEJMra054035.

14. Strazzullo P, D'Elia L, Kandala NB, Cappuccio FP. Salt intake, stroke, and cardiovascular disease: meta-analysis of prospective studies. BMJ. 2009;339:b4567. doi: 10.1136/bmj. b4567.

15. Esteghamati A, Gouya MM, Abbasi M, Delavari A, Alikhani S, Alaedini F, et al. Prevalence of diabetes and impaired fasting glucose in the adult population of Iran: National Survey of Risk Factors for Non-Communicable Diseases of Iran. Diabetes Care. 2008;31(1):96-8. doi: 10.2337/dc07-0959.

16. Latifi SM, Karandish M, Shahbazian H, Hardani Pasand L. Incidence of prediabetes and type 2 diabetes among people aged over 20 years in Ahvaz: a 5-year perspective study (2009-2014). J Diabetes Res. 2016;2016:4908647. doi: $10.1155 / 2016 / 4908647$.

17. Hadaegh F, Harati H, Ghanbarian A, Azizi F. Prevalence of coronary heart disease among Tehran adults: Tehran Lipid and Glucose Study. East Mediterr Health J. 2009;15(1):157-66.

18. Talaei M, Sarrafzadegan N, Sadeghi M, Oveisgharan S, Marshall T, Thomas GN, et al. Incidence of cardiovascular diseases in an Iranian population: the Isfahan Cohort Study. Arch Iran Med. 2013;16(3):138-44.

19. Javanbakht M, Baradaran HR, Mashayekhi A, Haghdoost AA, Khamseh ME, Kharazmi E, et al. Cost-of-Illness Analysis of Type 2 Diabetes Mellitus in Iran. PLoS One. 2011;6(10):e26864. doi: 10.1371/journal.pone.0026864.

20. Imani A, Gharibi F, Dadashi O, Najafi M, Mirbagheri SM. Analysis of Cardiovascular Diseases Costs and Their Effective Factors in Tabriz Hospitalized Patients, 2015. Jundishapur J Health Sci. 2016;8(2):e32503.

21. United Nations. Transforming our world: The 2030 agenda for sustainable development; United Nations: 2015.

22. Djalalinia S, Modirian M, Sheidaei A, Yoosefi M, Zokaiee H, Damirchilu B, et al. Protocol design for large-scale 
cross-sectional studies of surveillance of risk factors of noncommunicable diseases in Iran: STEPs 2016. Arch Iran Med. 2017;20(9):608-616.

23. Dreher LM. Whole Fruits and Fruit Fiber Emerging Health Effects. Nutrients. 2018;10(12):1833. doi: 10.3390/ nu 10121833 .

24. Hall JN, Moore S, Harper SB, Lynch JW. Global variability in fruit and vegetable consumption. Am J Prev Med. 2009;36(5):402-409.e5. doi: 10.1016/j.amepre.2009.01.029.

25. Weaver CM. How sound is the science behind the dietary recommendations for dairy? Am J Clin Nutr. 2014;99(5 Suppl):1217S-22S. doi: 10.3945/ajcn.113.073007.

26. Bonaccio M, Ruggiero E, Di Castelnuovo A, Costanzo S, Persichillo $M$, De Curtis $A$, et al. Fish intake is associated with lower cardiovascular risk in a Mediterranean population: Prospective results from the Moli-sani study. Nutr Metab Cardiovasc Dis. 2017;27(10):865-873. doi: 10.1016/j. numecd.2017.08.004.

27. Forouzanfar $\mathrm{MH}$, Afshin A, Alexander LT, Anderson HR, Bhutta ZA, Biryukov S, et al. Global, regional, and national comparative risk assessment of 79 behavioural, environmental and occupational, and metabolic risks or clusters of risks, 1990-2015: a systematic analysis for the Global Burden of Disease Study 2015. Lancet. 2016;388(10053):1659-1724. doi: 10.1016/S0140-6736(16)31679-8. Erratum in: Lancet. 2017 Jan 7;389(10064):e1.

28. Willett WC. Dietary fats and coronary heart disease. J Intern Med. 2012;272(1):13-24. doi: 10.1111/j.13652796.2012.02553.x.

29. Armstrong T, Bull F. Development of the World Health Organization Global Physical Activity Questionnaire (GPAQ). Journal of Public Health. 2006 2006/04/01;14(2):66-70.

30. Akbari F, Azadbakht L. A systematic review on diet quality among Iranian youth: focusing on reports from Tehran and Isfahan. Arch Iran Med. 2014;17(8):574-84.

31. Afshin A, Micha R, Khatibzadeh S, Schmidt LA, Mozaffarian D. Dietary Policies to Reduce Non-Communicable Diseases. In: Garrett W. Brown, Gavin Yamey, Sarah Wamala (Eds)ed. The Handbook of Global Health Policy. City of Country: John Wiley \& Sons, Ltd; 2014: 175-93.

32. Farahmand M, Amiri P, Ramezani Tehrani F, Momenan AA, Mirmiran P, Azizi F. What are the main barriers to healthy eating among families? A qualitative exploration of perceptions and experiences of Tehranian men. Appetite. 2015;89:291-7. doi: 10.1016/j.appet.2015.02.025.

33. Farahmand M, Tehrani FR, Amiri P, Azizi F. Barriers to healthy nutrition: perceptions and experiences of Iranian women. BMC Public Health. 2012;12:1064. doi: 10.1186/1471-245812-1064.

34. Lachat C, Otchere S, Roberfroid D, Abdulai A, Seret FMA, Milesevic J, et al. Diet and Physical Activity for the Prevention of Noncommunicable Diseases in Low- and MiddleIncome Countries: A Systematic Policy Review. PLoS Med. 2013;10(6):e1001465. doi: 10.1371/journal.pmed.1001465.

35. Moradi G, Mohammad K, Majdzadeh R, Ardakani HM, Naieni $\mathrm{KH}$. Socioeconomic Inequality of Non-Communicable Risk Factors among People Living in Kurdistan Province, Islamic Republic of Iran. Int J Prev Med. 2013;4(6):671-83.

36. Biranvandzadeh M, Heshmati jadid M, Sorkhkamal K. Assessment of Development Level of Sistan and Baluchistan Province Compared to other Iran's Provinces. International Journal of Architecture and Urban Development. 2015 12/01;5(1):69-76. en.
37. Irala-Estevez JD, Groth M, Johansson L, Oltersdorf U, Prattala R, Martinez-Gonzalez MA. A systematic review of socioeconomic differences in food habits in Europe: consumption of fruit and vegetables. Eur J Clin Nutr. 2000;54(9):706-14. doi: $10.1038 /$ sj.ejcn.1601080.

38. Heshmat R, Salehi F, Qorbani M, Rostami M, Shafiee G, Ahadi $Z$, et al. Economic inequality in nutritional knowledge, attitude and practice of Iranian households: The NUTRI-KAP study. Med J Islam Repub Iran. 2016;30:426.

39. Moradi G, Mohammad K, Majdzadeh R, Ardakani HM, Naieni $\mathrm{KH}$. Socioeconomic Inequality of Non-Communicable Risk Factors among People Living in Kurdistan Province, Islamic Republic of Iran. Int J Prev Med. 2013;4(6):671-83.

40. Rezazadeh A, Omidvar N, Eini-Zinab H, Ghazi-Tabatabaie M, Majdzadeh R, Ghavamzadeh S, et al. Major dietary patterns in relation to demographic and socio-economic status and food insecurity in two Iranian ethnic groups living in Urmia, Iran. Public Health Nutr. 2016;19(18):3337-3348. doi: 10.1017/ S1368980016001634.

41. Satia JA. Diet-related disparities: understanding the problem and accelerating solutions. J Am Diet Assoc. 2009;109(4):6105. doi: 10.1016/j.jada.2008.12.019.

42. Ramirez AG, Suarez L, Chalela P, Talavera GA, Marti J, Trapido EJ, et al. Cancer risk factors among men of diverse Hispanic or Latino origins. Prev Med. 2004;39(2):263-9. doi: 10.1016/j. ypmed.2004.03.034.

43. Mortazavi Z, Dorosty AR, Eshraghian MR, Ghaffari M, AnsariMoghaddam A, Mohammadi M. Household Food Insecurity in Southeastern Iran: Severity and Related Factors. Int J Food Sci. 2017;2017:7536024. doi: 10.1155/2017/7536024.

44. Mello JA, Gans KM, Risica PM, Kirtania U, Strolla LO, Fournier L. How is food insecurity associated with dietary behaviors? An analysis with low income, ethnically diverse participants in a nutrition intervention study. J Am Diet Assoc. 2010;110(12):1906-11. doi: 10.1016/j.jada.2010.09.011.

45. Hanson KL, Connor LM. Food insecurity and dietary quality in US adults and children: a systematic review. Am J Clin Nutr. 2014;100(2):684-92. doi: 10.3945/ajcn.114.084525.

46. Leung CW, Epel ES, Ritchie LD, Crawford PB, Laraia BA. Food insecurity is inversely associated with diet quality of lowerincome adults. J Acad Nutr Diet. 2014;114(12):1943-53.e2. doi: 10.1016/j.jand.2014.06.353.

47. Mohammadi-Nasrabadi F, Omidvar N, Khoshfetrat MR, Kolahdooz F. Household food insecurity in the Islamic Republic of Iran: a systematic review and meta-analysis. East Mediterr Health J. 2014;20(11):698-706.

48. Evans A, Banks K, Jennings R, Nehme E, Nemec C, Sharma S, et al. Increasing access to healthful foods: a qualitative study with residents of low-income communities. Int J Behav Nutr Phys Act. 2015;12 Suppl 1(Suppl 1):S5. doi: 10.1186/14795868-12-S1-S5.

49. Seguin R, Connor L, Nelson M, LaCroix A, Eldridge G. Understanding Barriers and Facilitators to Healthy Eating and Active Living in Rural Communities. J Nutr Metab. 2014;2014:146502. doi: 10.1155/2014/146502.

50. Evans A, Banks K, Jennings R, Nehme E, Nemec C, Sharma S, et al. Increasing access to healthful foods: a qualitative study with residents of low-income communities. Int J Behav Nutr Phys Act. 2015;12 (Suppl 1):S5. doi: 10.1186/1479-5868-12S1-S5.

51. Neff RA, Palmer AM, McKenzie SE, Lawrence RS. Food Systems and Public Health Disparities. J Hunger Environ Nutr. 2009;4(3-4):282-314. doi: 10.1080/19320240903337041. 